\title{
Processes governing phytoplankton blooms in estuaries. I: The local production-loss balance
}

\author{
Lisa V. Lucas ${ }^{1, *}$, Jeffrey R. Koseff ${ }^{2}$, James E. Cloern ${ }^{1}$, Stephen G. Monismith ${ }^{2}$, \\ Janet K. Thompson ${ }^{1,2}$
}

${ }^{1}$ United States Geological Survey, 345 Middlefield Road, MS \#496, Menlo Park, California 94025, USA

${ }^{2}$ Environmental Fluid Mechanics Laboratory, Dept. of Civil and Environmental Engineering, Stanford University, Stanford, California 94305-4020, USA

\begin{abstract}
The formation and spatial distribution of phytoplankton blooms in estuaries are controlled by (1) local mechanisms, which determine the production-loss balance for a water column at a particular spatial location (i.e. control if a bloom is possible), and (2) transport-related mechanisms, which govern biomass distribution (i.e. control if and where a bloom actually occurs). In this study, the first of a 2-paper series, we use a depth-averaged numerical model as a theoretical tool to describe how interacting local conditions (water column height, light availability, benthic grazing) influence the local balance between phytoplankton sources and sinks. We also explore trends in the spatial variability of the production-loss balance across the topographic gradients between deep channels and lateral shoals which are characteristic of shallow estuaries. For example, under conditions of high turbidity and slow benthic grazing the highest rates of phytoplankton population growth are found in the shallowest regions. On the other hand, with low turbidity and rapid benthic grazing the highest growth rates occur in the deeper areas. We also explore the effects of semidiurnal tidal variation in water column height, as well as spring-neap variability. Local population growth in the shallowest regions is very sensitive to tidal-scale shallowing and deepening of the water column, especially in the presence of benthic grazing. A spring-neap signal in population growth rate is also prominent in the shallow areas. Population growth in deeper regions is less sensitive to temporal variations in tidal elevation. These results show that both shallow and deep regions of estuaries can act as sources or sinks for phytoplankton biomass, depending on the local conditions of mean water column height, tidal amplitude, light-limited growth rate, and consumption by grazers.
\end{abstract}

KEY WORDS: Phytoplankton $\cdot$ Estuaries $\cdot$ Model $\cdot$ Benthic grazing $\cdot$ Bathymetry $\cdot$ Light

\section{INTRODUCTION}

Phytoplankton blooms are key components of coastal ecosystem dynamics. Our interest in blooms is motivated by (1) growing concern about changing bloom dynamics (frequency, duration, magnitude, species composition) as an element of global change, especially as a response to anthropogenic nutrient enrichment of coastal waters (Anderson \& Garrison 1997); and (2) our evolving understanding of blooms as biological mechanisms of rapid transformation of nutri-

\footnotetext{
·E-mail: 1lucas@usgs.gov
}

ents, trace metals, and carbon (e.g. Cloern 1996). Our conceptual model describes blooms as population responses to changing physical dynamics (Legendre 1990), such as the establishment of fronts (Franks 1992), formation of vertical stratification (Koseff et al. 1993), or hydrologic changes in residence time (Relexans et al. 1988). Our conceptual model also includes recognition that blooms are patchy-phytoplankton biomass is spatially heterogeneous. For example, observations by Huzzey et al. (1990) in South San Francisco Bay (see Fig. 1) demonstrate large spatial gradients and rapid temporal evolution of those spatial patterns during the 1982 spring bloom. We understand, in general, that patchiness like that shown in Fig. 1 arises from 2 kinds 
of processes: (1) spatial variability in population dynamics, and (2) spatially variable transports of water and plankton. The former is the result of horizontal variations in the local balance between phytoplankton production and loss (i.e. local combinations of water column height, turbidity, grazing rates, etc.). Such local conditions control net population growth rates for a water column at a particular spatial location and, thus, determine if a bloom is possible. The second process governing bloom patchiness-transport-provides communication between different subenvironments within a system, over both short (on the order of hours) and long (on the order of weeks) time scales. Transport determines the conditions experienced by the plankton while and after it grows and, thus, controls if and where a bloom actually occurs. Therefore, while local conditions control population growth rates, large-scale transport processes control biomass concentrations and distribution. In order to understand bloom occurrence and patchiness, we must investigate the interactions governing both local mechanisms and transport-related processes.

This and the companion paper (Lucas et al. 1999, in this issue) present a theoretical study in which we use numerical experiments of phytoplankton population dynamics with a 2-dimensional hydrodynamic model to illustrate how local- and transport-related processes can influence bloom formation (i.e. whether a bloom occurs) and bloom patchiness (i.e. where a bloom is observed) in a shallow estuary. Our study was motivated to understand the mechanisms that can give rise to the kind of spatial and temporal variability illustrated in Fig. 1. We emphasize, though, that the goal of this work is to explore the sensitivity of estuarine phytoplankton dynamics to various processes, as opposed to faithfully reproducing in detail an observed bloom event.

Both papers are new contributions to a series of numerical investigations designed to search for general principles of bloom development in estuaries. They build from previous investigations which used 1-dimensional vertical models (Cloern 1991, Koseff et
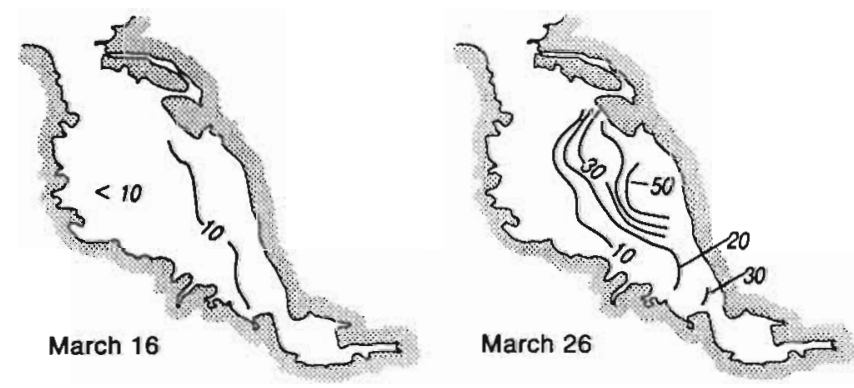

Fig. 1. Observed chlorophyll a distributions (in $\mathrm{mg} \mathrm{m}^{-3}$ ) in South San Francisco Bay during spring 1982 (from Huzzey et al. 1990, Fig. 5) al. 1993, Lucas et al. 1998) and a pseudo-2-dimensional model (Vidergar et al. 1993, Lucas 1997, Lucas et al. unpubl., Thompson et al. unpubl.) to explore interactions between density stratification, vertical mixing, sinking, light-limited production, and grazing by zooplankton and benthic invertebrates to define the sets of conditions under which blooms can develop. The 1-dimensional approach assumed horizontal uniformity as a simplification that permitted a systematic exploration of vertical processes. For example, in the first paper, Cloern (1991) demonstrated the importance of variations in vertical mixing intensity over the spring-neap cycle. In the second paper, Koseff et al. (1993) illustrated the significance of hourly scale fluctuations in vertical mixing and the requirement of density stratification for bloom inception in a turbid channel region subject to rapid consumption by benthic invertebrates. In the third paper, Lucas et al. (1998) explored the details of vertical stratification and their effects on 'leakage' of phytoplankton biomass from a surface layer and constraints on bloom development. The pseudo-2-dimensional model (Vidergar et al. 1993, Lucas 1997, Lucas et al. unpubl., Thompson et al. unpubl.) maintained vertical variability while adding idealized lateral transport and provided a first look at the significance of shoal-channel exchange in systemwide bloom dynamics. Here, we employ a 'vertically well-mixed' assumption (which we justify below) and consider more detailed horizontal transport and variability. We use this incremental approach of systematically considering the separate effects of vertical and then horizontal processes as a rational progression toward development of a full 3-dimensional representation of estuarine phytoplankton dynamics.

In this paper, we present our approach to modeling the biology, and then focus on local mechanisms controlling phytoplankton population growth in a shallow, tidally driven, turbid estuary where algal grazing by benthic consumers may be rapid. In the companion paper (Lucas et al. 1999), we discuss details of the hydrodynamic modeling approach and then identify several nonlocal mechanisms involving horizontal transport and its interaction with spatially variable local processes in controlling system-level bloom dynamics. Our study of the local processes in this first paper, without the added complexities associated with transport, provides the basis for interpreting systemwide, transport-influenced bloom dynamics in the companion paper.

We use South San Francisco Bay (SSFB) as a representative case for illustrating typical bathymetric variations and their effects on the distribution of phytoplankton sources and sinks in a shallow estuary (this paper), as well as representative transport-related mechanisms controlling system-level bloom dynamics 
(Lucas et al. 1999). SSFB is a large subsystem of San Francisco Bay and is characterized by a deep channel (approx. 10 to $15 \mathrm{~m}$ deep) bounded by broad subtidal shoals (approx. 2 to $6 \mathrm{~m}$ deep) and intertidal mudflats (see Fig. 2). Under conditions of peak freshwater flow from the Sacramento-San Joaquin River Delta, SSFB may become significantly fresher and in some years even sustain persistent density stratification in the channel for several days (Lucas et al. 1998). Local runoff delivered to SSFB via smaller creeks, as well as effluent from sewage treatment plants, can also influ-

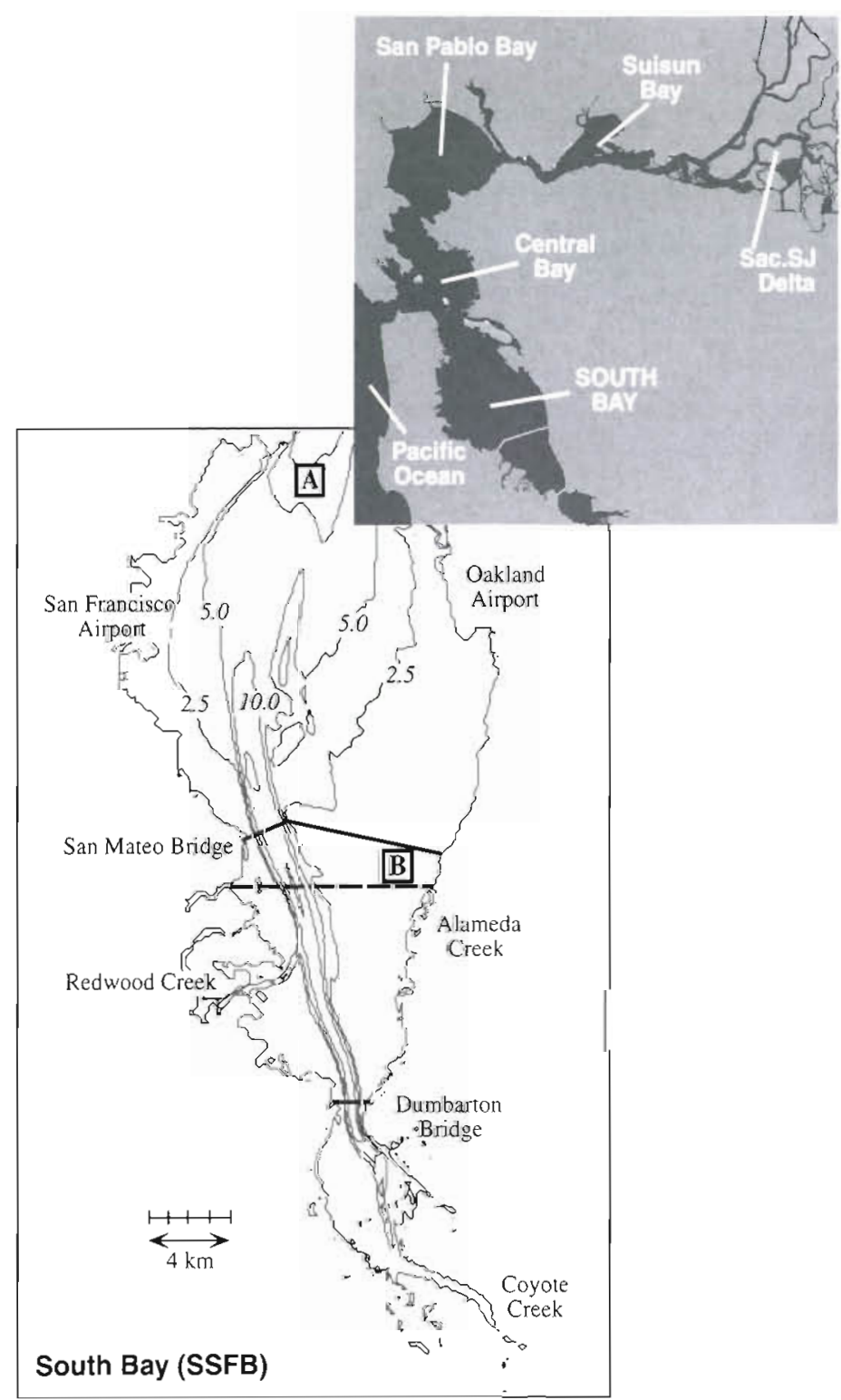

Fig. 2. South San Francisco Bay, with depth contours (mean tide level) shown in meters. Inset shows proximity to northern San Francisco Bay and Sacramento-San Joaquin River Delta. Dashed line: lateral transect in Figs $8 \& 9$. A and B: locations corresponding to the deep site and shallow site, respectively, referred to in Fig. 4 ence the water density distribution in SSFB. The impact of freshwater input on the hydrodynamics of SSFB, however, is mediated by wind and, more importantly, the tides. Both the semidiurnal tide (with mean amplitude $\approx 2 \mathrm{~m}$ ) and its fluctuation over the springneap cycle are significant in regulating the amount of turbulent mixing present in the water column to counter the stabilizing effects of freshwater inputs. This strong tidal influence, coupled with the shallow depths in SSFB, typically results in vertically wellmixed conditions, with stratification usually only of the 'strain-induced periodic' (or SIPS) type (see Simpson et al. 1990 for a description)

Although we use geometry, physical forcing, and biological parameter ranges characteristic of SSFB, the purpose of this modeling study is to develop general insights into physical-biological mechanisms potentially important to a large class of estuaries. The overall goal of both papers is to address several fundamental questions. In this paper, we ask: (1) How are bloom dynamics related to local conditions which control the balance between the phytoplankton source (primary production) and loss (respiration, grazing) at a specific location? How does water column height influence this local production-loss balance? (2) How do local sources and sinks of phytoplankton biomass vary spatially as a function of bathymetry? (For example, for a given set of conditions, which regions in an estuary have the potential to serve as the primary sources of phytoplankton biomass to the overall system?) (3) How does the local production-loss balance vary temporally, as a function of tidally varying water column height?

Building on the information presented in this paper, the second paper (Lucas et al. 1999) addresses the following: (4) How do tidally driven low-frequency (residual) transport processes interact with spatialtemporal variability of local conditions to control phytoplankton bloom development and location in an estuary? (5) How do tidally driven high-frequency (tidal-time-scale) transport processes interact with spatial-temporal variability of local conditions to control phytoplankton bloom development and location? (6) Do regions with local conditions favorable to bloom development always sustain high phytoplankton biomass? Do regions with local conditions unfavorable to bloom development necessarily have very low biomass?

The first 2 questions are central to the bloom problem because many shallow coastal ecosystems (estuaries, tidal rivers, lagoons) have complex bottom topography, with regions of shallow water connected to regions of deep water by circulation and mixing processes. The shallow and deep domains provide very different environments for the production of phyto- 
plankton biomass. For example, the shallow domains of San Francisco Bay can be zones of rapid phytoplankton population growth because production may be light-limited and mean irradiance is inversely proportional to water column height (Alpine \& Cloern 1988). Phytoplankton losses, such as grazing by benthic suspension-feeders, also vary with water column height. Although coastal ecosystems provide a spatial mosaic of environments for net phytoplankton growth. we do not understand well how this horizontal variability of the production-loss balance governs the initiation and patchiness of blooms. Spatial mapping often shows highest biomass (chlorophyll concentration) in the shallow domains of San Francisco Bay (Cloern et al. 1985), and this same general pattern has been observed in other estuaries such as the Ems-Dollard, The Netherlands (Colijn 1982), Delaware Bay, USA (Pennock 1985), and Chesapeake Bay, USA (Malone et al. 1986). Numerical modeling has also suggested significant differences between the growth environments in deep and shallow regions (Cloern \& Cheng 1981, Vidergar et al. 1993). Is there a general rule that shallow domains are always regions of positive net phytoplankton population growth?

The third question above is important because the bloom-patchiness problem in tidal systems is further complicated by water-level fluctuations. As an example, San Francisco Bay has a mean depth of $6 \mathrm{~m}$ (Conomos et al. 1985) and a tidal amplitude of 1 to $2 \mathrm{~m}$, so the water column height changes (on average) by 15 to $30 \%$ over the semidiurnal tidal period. This tidalscale variability is especially important in the shallow subtidal and intertidal domains where an overlying water column forms and disappears with each tidal cycle. Thus, the spatial pattern of phytoplankton growth environments is not static, but instead is dynamic over the tidal period. The interaction between water-level fluctuation and bottom topography (i.e. temporal and spatial variability in the local production-loss balance) could be a key mechanism that regulates bloom formation and patchiness in shallow tidal systems. This hypothesis guided the specific numerical experiments described below.

\section{MODELING APPROACH}

Our general approach is to include the key biological processes relevant to bloom development, but to describe these with minimal complexity. For example, since our objective is to understand the early stages of blooms, and since blooms usually begin when nutrient concentrations are above limiting levels, we do not include explicit simulation of coupled phytoplanktonnutrient dynamics here. Furthermore, our model- building is done as a complement to a long-term study of San Francisco Bay (Cloern 1996) and is driven by questions arising from field observations and modeling of that system. However, since the goal of this work is to search for general relationships and since the spatial distributions of key parameters (e.g. benthic grazing rates, light attenuation coefficients) vary between systems and seasonally, we have opted for uniform (or near-uniform, in Lucas et al. 1999) distributions of these parameters. Certainly, incorporating more detailed spatial and temporal variability for benthic grazing and turbidity would add another layer of complexity to the concepts we demonstrate here and would compound the effects of bathymetry discussed in later sections. Without understanding the most basic case, however, understanding the more complicated case would be extremely difficult.

The hydrodynamic model which formed the basis of this modeling effort is TRIM2D (Casulli 1990a, b, Cheng et al. 1993), a depth-averaged hydrodynamic model of tidal flow in a bathymetrically complex estuary. Because the model equations are vertically averaged, each transported variable is assumed to be uniform in the vertical dimension. This approach automatically precludes investigation of the effects of vertical density stratification, which has been shown in certain scenarios to be crucial to bloom development (Koseff et al. 1993, Lucas et al. 1998). Here we use the depth-averaged model in the context of SSFB, which is representative of a class of estuaries which are usually well-mixed in the vertical or only subject to SIPS on the semidiurnal time scale. Modeling has shown that the effect on bloom initiation of stratification formation and erosion over such short time scales is hardly different from the effect of an unstratified condition (Lucas et al. 1998). Thus, for the purposes of modeling phytoplankton dynamics, the assumption of vertical scalar homogeneity is appropriate for a large class of shallow coastal systems such as Boston Harbor, USA (Signell \& Butman 1992), the Dutch Wadden Sea (Zimmerman 1976), and the Bay of Brest, France (Le Pape et al. 1996), for which density stratification is generally absent or ephemerai.

\section{Incorporation of phytoplankton dynamics into TRIM2D}

Incorporation of phytoplankton dynamics into the TRIM2D hydrodynamic model (to produce TRIM-BIO) required description of phytoplankton growth, consumption, and transport. Thus, a growth/consumption term was added to the vertically averaged conservative scalar transport equation for the case of phytoplankton, giving: 


$$
\begin{aligned}
\frac{\partial(H \bar{B})}{\partial t}+ & \frac{\partial}{\partial x}(U \bar{B} H)+\frac{\partial}{\partial y}(V \bar{B} H)= \\
& \frac{\partial}{\partial x}\left(K_{\mathrm{h}} \frac{\partial(H \bar{B})}{\partial x}\right)+\frac{\partial}{\partial y}\left(K_{\mathrm{h}} \frac{\partial(H \bar{B})}{\partial y}\right)+\mu_{\mathrm{eff}} \bar{B} H
\end{aligned}
$$

where $x$ and $y$, respectively, denote streamwise and cross-stream distance; $\bar{B}(x, y, t)$ is the depth-averaged phytoplankton biomass concentration at time $t_{i} \mu_{\text {efi }}(x, y, t)$ is the effective rate of depth-averaged phytoplankton growth; $H(x, y, t)$ is the total water column height; $U(x, y, t)$ and $V(x, y, t)$ are vertically averaged velocities in the $x$ and $y$ directions, respectively; and $K_{\mathrm{h}}(x, y, t)$ is the horizontal diffusion coefficient. $\mu_{\text {eif }}$ accounts for depth-variable light availability, instantaneous local water column height, respiration, zooplankton grazing, and benthic grazing. $\mu_{\text {ent }}$ is calculated during every time step at every horizontal gridpoint and is, therefore, a function of the current local phytoplankton biomass, turbidity, benthic grazing rate, and water-surface elevation.

The incorporation of benthic grazing into the general form of $\mu_{\text {eff }}$ is accomplished by depth-averaging the vertical phytoplankton transport equation over the water column height, $H$ :

$$
\begin{aligned}
& \frac{1}{H} \int_{-H}^{0} \frac{\partial B}{\partial t} \mathrm{~d} z+\frac{1}{H} \int_{-H}^{0}\left[\frac{\partial(w B)}{\partial z}-\frac{\partial}{\partial z}\left(K_{z} \frac{\partial B}{\partial z}\right)\right] \mathrm{d} z \\
& =\frac{1}{H} \int_{-H}^{0} \mu_{\text {net }} B \mathrm{~d} z
\end{aligned}
$$

$B(z, t)$ is the depth- and time-variable phytoplankton biomass in [mg chl $a \mathrm{~m}^{-3}$ ]; $z$ is the depth in [m] $(z=0$ at the water surface, $z=-H$ at the benthic boundary); $\mu_{\text {net }}(z, t)$ is the net phytoplankton growth (gross growth minus respiration and zooplankton grazing losses) in $\left[\mathrm{d}^{-1}\right]_{i} w$ is the vertical velocity of the phytoplankton in $\left[\mathrm{m} \mathrm{d}^{-1}\right]$, which, in the interior of the water column, is assumed to equal the phytoplankton sinking rate, $W_{s}$; and $K_{z}(z, t)$ is the vertical turbulent diffusivity in $\left[\mathrm{m}^{2} \mathrm{~d}^{-1}\right]$. Carrying out the integration:

$$
\frac{\partial \bar{B}}{\partial t}+\frac{1}{H}\left[w B-K_{z} \frac{\partial B}{\partial z}\right]_{-H}^{0}=\overline{\mu_{\text {net }} B}
$$

where the overbar represents an average over total depth $H$. We apply the following conditions at the top and bottom boundaries (Koseff et al. 1993):

$$
\begin{gathered}
\left(w B-K_{z} \frac{\partial B}{\partial z}\right)_{z=0}=0 \\
\left(w B-K_{z} \frac{\partial B}{\partial z}\right)_{z=-H}=-\alpha B_{(z=-H)}
\end{gathered}
$$

where $\alpha$ is the benthic grazing rate in $\left[\mathrm{m}^{3} \mathrm{~m}^{-2} \mathrm{~d}^{-1}\right]$. Condition (4) enforces zero flux of phytoplankton at the water surface, and Condition (5) limits the bottom flux of phytoplankton to a benthic grazing flux cast in advective form. Substitution of Conditions (4) \& (5) into Eq. (3) produces the following:

$$
\frac{\partial \bar{B}}{\partial t}+\frac{1}{H}\left[0-\left(-\alpha B_{(z=-H)}\right)\right]=\overline{\mu_{\mathrm{net}} B}
$$

If turbulent mixing is vigorous (see Koseff et al. 1993) such that $B$ is approximately uniform over the full depth, then we can assume the following:

$$
\vec{B}=B_{(z=0)}=B_{(z=-H)}=B_{(\operatorname{any} z)}
$$

Eq. (7) allows us to decompose the growth term as follows:

$$
\overline{\mu_{\text {net }} B}=\overline{\mu_{\text {net }} \bar{B}}=\overline{\mu_{\text {net }}} \bar{B}
$$

Thus, under the assumption of 'well-mixedness', Eq. (6) becomes:

$$
\begin{aligned}
\frac{\partial \bar{B}}{\partial t} & =\overline{\mu_{\mathrm{net}}} \bar{B}-\frac{\alpha \bar{B}}{H} \\
& =\left(\overline{\mu_{\mathrm{net}}}-\frac{\alpha}{H}\right) \bar{B} \\
& =\mu_{\mathrm{eff}} \bar{B}
\end{aligned}
$$

Eq. (9) provides a general approach for calculating the growth of a vertically uniform phytoplankton population subject to grazing at the bottom boundary. The assumption inherent to Eq. (9) (i.e. of vertically homogeneous scalar concentrations) is consistent with the TRIM2D vertically averaged model and allows us to substitute $B$ for $\bar{B}$ in the depth-averaged simulations described below.

One condition which must be satisfied for the assumption of vertical homogeneity (Eq. 7) to be valid is the dominance of vertical mixing over sinking. The relation between mixing and sinking of the phytoplankton can be parameterized in terms of the turbulent Peclet number, $P e_{\mathrm{t}}=W_{\mathrm{s}} H / K_{2} . P e_{\mathrm{t}}$ is the ratio of a time scale for mixing through the water column $\left(\tau_{\text {mix }} \approx\right.$ $\left.H^{2} / K_{z}\right)$ to a time scale for sinking $\left(\tau_{\text {sink }} \approx H / W_{\mathrm{s}}\right)$. If $\tau_{\text {mix }}$ is small relative to $\tau_{\text {sink }}$ (i.e. $P e_{t} \ll 1$ ), then mixing is fast relative to sinking, and the water column is approximately homogeneous. On the other hand, if $\tau_{\mathrm{mix}}$ is long relative to $\tau_{\operatorname{sink}}$ (i.e. $P e_{t} \geqslant 1$ ), then sinking is dominant, potentially producing vertical inhomogeneities. Thus, Eq. (7) is only valid when $P e_{\mathrm{t}}$ is small. A typical value of $P e_{t}$ for shallow regions of SSFB is $P e_{t} \approx$ (0.5)(2)/100 0.01, and a typical value for the channe] is $P e_{\mathrm{t}}=(0.5)(15) / 1000 \sim 0.01$ (see Fischer et al. 1979 for estimates of $K_{z}$ ). The choice of $W_{\mathrm{s}}=0.5 \mathrm{~m} \mathrm{~d}^{-1}$ is appropriate for actively growing nanoplankton-dominated communities (Cloern 1991). Since the typical size of $P e_{1}$ for both channel and shoal domains is small, our assumption of vertical well-mixedness of the phytoplankton is appropriate, especially for the early stages of bloom development. 


\section{Calculating the effective phytoplankton growth rate, $\mu_{\text {eif }}$}

In the previous section, the effective rate of depthaveraged phytoplankton growth in a well-mixed water column was shown to equal the sum of $\overline{\mu_{\text {net }}}$ (which incorporates all pelagic processes) and $-\alpha / H_{\text {, }}$ the loss to benthic grazing. In TRIM-BIO, values of $\alpha$ are based on measurements of benthic bivalve biomass in SSFB (Thompson 1999) and account for effects of concentration boundary layers (O'Riordan et al. 1995). The $H$ in this loss term is taken as the instantaneous, local water column height. Our approach for calculating $\overline{\mu_{\text {net }}}$, the pelagic portion of $\mu_{\text {elf }}$ is summarized here.

$\overline{\mu_{\text {net }}}$ is based on the general form:

$$
\overline{\mu_{\text {net }}}=\bar{P} \cdot(\text { chl }: C)-r e s p-Z P
$$

where $\bar{P}$ is the daily, depth-averaged rate of photosynthesis (carbon assimilation per unit of chlorophyll biomass), chl:C is the cellular ratio of chlorophyll $a$ to carbon in phytoplankton, resp is the rate of loss to respiration, and $Z P$ is the zooplankton grazing rate.

The calculation of chl:C is based on the approach of Cloern et al. (1995), who suggested the following functional dependence of chl:C on temperature $T$, dayaveraged, depth-averaged irradiance $\widetilde{\bar{T}}$, and nutrientlimited growth rate $\mu^{\prime}$ :

$$
\text { chl }: C=0.003+0.0154 \exp (0.050 T) \exp (-0.05 \widetilde{\widetilde{I I}}) \mu^{\prime}
$$

This empirical model describes an adaptive rate of chlorophyll synthesis which decreases with increased light and increases with increased nutrient availability. Although TRIM-BIO does not explicitly calculate phytoplankton-nutrient dynamics, we have assumed a simple hyperbolic dependence of $\mu^{\prime}$ on phytoplankton biomass $B$ which reflects nutrient limitation $\left(\mu^{\prime} \approx 0\right)$ for very large $B$ and no nutrient limitation $\left(\mu^{\prime} \approx 1\right.$ ) for very small $B$ (Lucas 1997). These assumptions are consistent with observations in SSFB (Cloern 1996) and other estuaries of strong inverse correlations between phytoplankton biomass and nutrient concentrations. This ad hoc representation of nutrient limitation was included to constrain the magnitude of blooms in long-term simulations.

Irradiance in the water column is attenuated by both abiotic and biotic (self-shading) components and decreases exponentially with depth. The abiotic light attenuation coefficient, $k_{\ell}$, is based on SSFB field measurements (Thompson 1999). Self-shading is incorporated by adding a biotic component of light attenuation, calculated as the chlorophyll-specific attenuation $\left(0.016 \mathrm{~m}^{2} \text { ( } \mathrm{mg} \mathrm{chl} a\right)^{-1}$ ) multiplied by the chlorophyll biomass [mg chl a $\mathrm{m}^{-3}$ ] (Bannister 1974).
The algal respiration, resp, is the sum of a fixed basal rate and a component associated with cell synthesis and proportional to the variable specific growth rate (Cloern et al. 1995). The zooplankton grazing rate, $Z P$, is assumed to be a constant $0.1 \mathrm{~d}^{-1}$, based on seasonal studies of the zooplankton community composition, abundance, and size-dependent grazing in SSFB (Cloern 1982)

Calculation of $\bar{P}$ is based on the following asymptotic function of local, instantaneous photosynthesis (Webb et al. 1974):

$$
p(z, t)=p_{\max }\left[1-\exp \left(-I(z, t) a / p_{\max }\right)\right]
$$

where $p_{\max }$ is the maximum local, instantaneous photosynthetic rate $\left[\mathrm{mg} C(\mathrm{mg} \mathrm{chl} a \mathrm{~h})^{-1}\right], I(z, t)$ is the irradiance at depth $z$ and time $t\left[\mu \mathrm{mol} \mathrm{m} \mathrm{m}^{-2} \mathrm{~s}^{-1}\right.$, and $a$ defines the photosynthetic efficiency at low irradiance [( $\left.\mathrm{mg} \mathrm{C}(\mathrm{mg} \text { chl } a \mathrm{~h})^{-1}\right)$ (umol m $\left.\left.\mathrm{m}^{-2} \mathrm{~s}^{-1}\right)^{-1}\right]$. The daily, depth-averaged rate of photosynthesis, $\bar{P}$, is then represented by:

$$
\begin{aligned}
\bar{P} & =\frac{1}{H} \int_{0}^{24} \int_{-H}^{0} p \mathrm{~d} z \mathrm{~d} t \\
& =\frac{1}{H} \int_{0}^{24} \int_{-H}^{0} p_{\max }\left[1-\exp \left(-I(z, t) a / p_{\max }\right)\right] \mathrm{d} z \mathrm{~d} t
\end{aligned}
$$

To estimate the double integral in Eq. (13), we use (following Cloern et al. 1995) the polynomial approximation of Platt et al. $(1990,1991)$. This analytical solution requires, in addition to $p_{\max }$ and $a$, values for surface irradiance, photoperiod, light attenuation coefficient, and water column height. Parameter values used in this study (Table 1) are based on measurements in SSFB during February and March of 1993 and 1994 (Caffrey et al. 1994, Edmunds et al. 1995, Thompson 1999), because the SSFB spring bloom typically begins during one of those months.

To summarize, the procedure for calculating the effective phytoplankton growth rate, $\mu_{\text {eff }}$, is as follows: (1) Specify $\alpha$ and $k_{t}$. (2) Specify surface irradiance, photoperiod, P-I parameters, water temperature. (3) Calculate irradiance in the water column; update dayaveraged irradiance for chl:C calculation. (4) Estimate $\mu^{\prime}$. (5) Calculate chl:C. (6) Solve for $\bar{p}$. (7) Calculate $\overline{\mu_{\text {net }}}\left(\right.$ Eq . 10). (8) Calculate $\mu_{\text {eff }}=\overline{\mu_{\text {net }}}-\alpha / H$.

Steps (3) through (8) are performed at every horizontal grid location during every time step of a TRIM-BIO simulation. Thus, the phytoplankton growth rate reflects a local balance between production driven by the water column irradiance and loss to benthic and pelagic consumption - a balance which can shift values of $\mu_{\text {eff }}$ from positive to negative, depending on spatial location and tidal phase. 


\section{LOCAL MECHANISMS}

\section{Dependence of population growth on water column height}

Here, we examine the dependence of $\mu_{\text {eff }}$ on $H$. Recall that the effective rate of depth-averaged phytoplankton growth takes the general form:

$$
\mu_{\mathrm{cfí}}=\overline{\mu_{\text {net }}}-\frac{\alpha}{H}
$$

where $\overline{\mu_{\text {net }}}$ includes all pelagic processes (carbon assimilation, chlorophyll synthesis, respiration, zooplankton grazing), and $-\alpha / H$ is the benthic grazing component. For the purposes of the current discussion, we rename these 2 components $\mu_{\text {pelagic }}$ and $\mu_{\text {benthic }}$ respectively, as a simple reminder of the primary dependence of each term. Thus, the effective (net) rate of population growth reflects the balance between the net pelagic source ( $\left.\mu_{\text {pelagic }}\right)$ and the benthic sink ( $\left.\mu_{\text {benthic }}\right)$ of phytoplankton biomass:

$$
\mu_{\text {eif }}=\mu_{\text {pelagic }}+\mu_{\text {benthic }}
$$

where:

$$
\mu_{\text {pelagic }}=\overline{\mu_{\text {net }}}=\bar{P} \cdot(\text { chl }: C)-\text { resp }-Z P
$$

and

$$
\mu_{\text {benthuc }}=-\frac{\alpha}{H}
$$

\section{Dependence of $\mu_{\text {pelagic }}$ on $H$}

Examination of the dependence of chl: $C$ and photosynthesis $\vec{P}$ on irradiance reveals opposite functional relationships. Specifically, chl:C decreases as irradiance increases (i.e. the phytoplankton synthesize less chlorophyll if more light is available); whereas, $\bar{P}$ increases as irradiance increases (i.e. assimilation of new cellular carbon is more rapid if more light is available) (Cloern et al. 1995). Thus, for a given $k_{t}$, chl: $C$ increases and $\bar{P}$ decreases as $H$ increases, since depth-averaged irradiance varies inversely with $H$. These relationships are shown in Fig. $3 a$ for a $k_{t}$ of $1.5 \mathrm{~m}^{-1}$, the physiological/environmental parameters listed in Table 1 , and a water column height $H$ assumed to be constant in time. Note that the rate of change of each of these quantities with respect to total depth (i.e. the magnitude of the slope of the curvel is greater for smaller $H$ than for larger $H$. The combined effect of these 2 functional relationships on $\mu_{\text {pelagic }}$ is shown in Fig. $3 \mathrm{~b}$, which reveals a general increase of $\mu_{\text {pelagic as }} H$ decreases (due to the overall dominance of the $\bar{P}-\bar{I}$ relationship), then a reversal of this trend for very small $H$ (due to the increasing importance of the chl:C-I relationship for progressively shallower depths). Thus, for deeper water columns, $\mu_{\text {pelagic }}$ is dominated by limitations in light availability, whereas $\mu_{\text {pelagıc }}$ in very shallow water columns is limited by photoinhibition of chlorophyll synthesis. However, the $\mu_{\text {pelagic }}-H$ curve follows the overall trend of the $\bar{P}$ - $H$ curve, indicating a general dominance of $\bar{P}$ effects on $\mu_{\text {pelagic }}$. Note further that, similar to chl:C and $\bar{P}$, the 


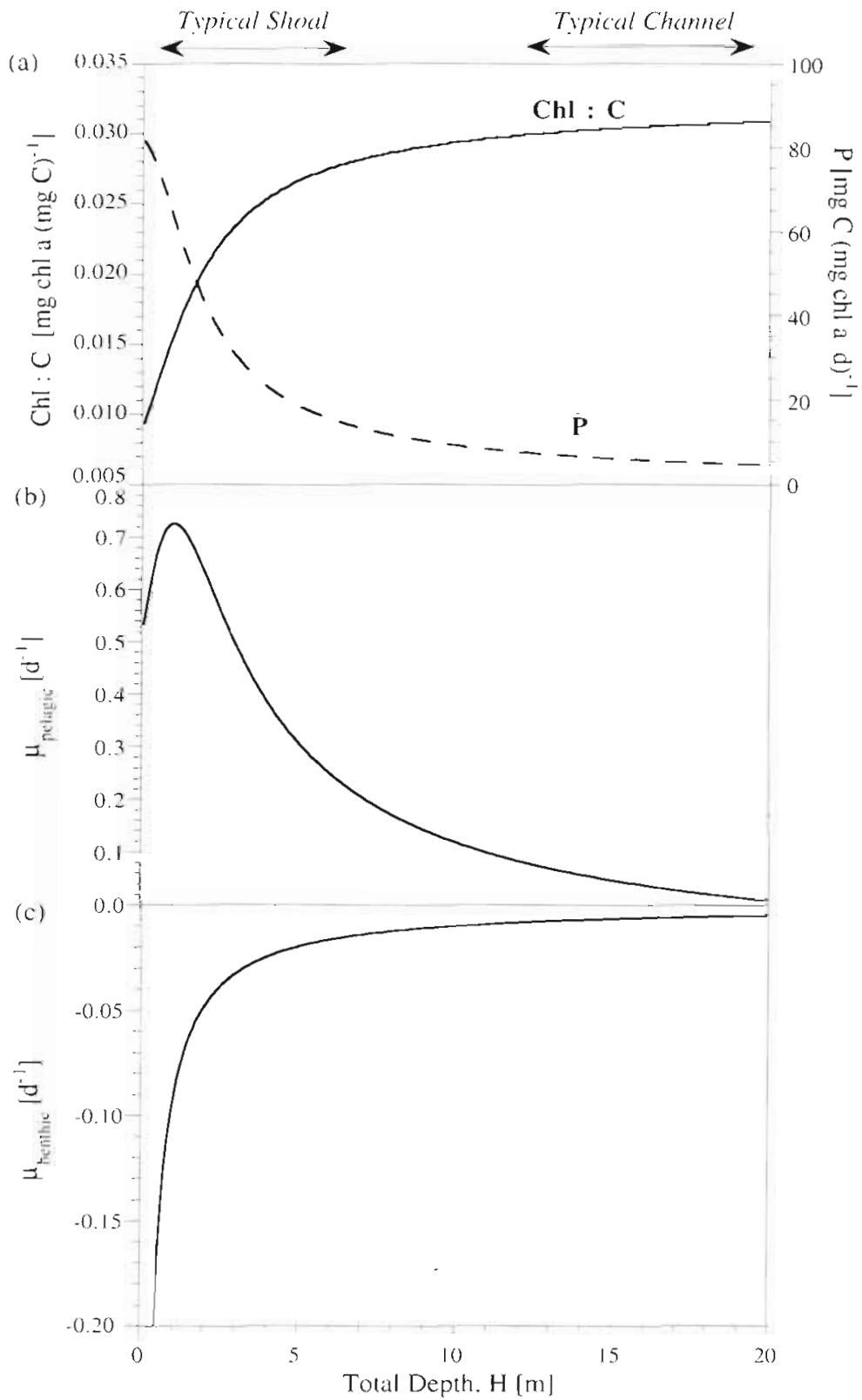

Fig. 3. (a) Chl:C (phytoplankton cellular ratio of chlorophyll a to carbon) and $\bar{P}$ (photosynthetic rate), (b) $\mu_{\text {pelagic }}$ (pelagic portion of effective phytoplankton growth rate), and (c) $\mu_{\text {benthic }}$ (benthic sink) versus total depth $(H)$ for light attenuation $k_{t}=1.5 \mathrm{~m}^{-1}, \alpha=0.1 \mathrm{~m}^{3} \mathrm{~m}^{-2} \mathrm{~d}^{-1}$, and other parameter values listed in Table 1

rate of change of $\mu_{\text {peiagic }}$ with respect to depth generally increases (i.e. the slope is generally steeper) for smaller $H$.

$$
\text { Dependence of } \mu_{\text {benthic }} \text { on } H
$$

The influence of benthic grazing on the overall rate of phytoplankton population growth increases as total depth $H$ decreases (i.e. as the water column shallows, the access of the benthos to the phytoplankton population in the water column is enhanced). The plot of $\mu_{\text {benthic }}$ versus $H$ in Fig. $3 c$ for a benthic grazing rate of $0.1 \mathrm{~m}^{3} \mathrm{~m}^{-2}$ $\mathrm{d}^{-1}$ also demonstrates that the rate of change of $\mu_{\text {benthic }}$ with respect to $H$ (i.e. the slope of the curve) increases with decreasing $H$. Notice further that the $\mu_{\text {benthic }}-H$ curve approaches zero and its slope is almost zero for depths greater than about $10 \mathrm{~m}$, suggesting that (for this small $\alpha$ ) the effect of benthic grazing on phytoplankton population growth is negligible for deep water columns.

Requirements for balanced population growth

If the reversal in the $\mu_{\text {pelagic }}-H$ relationship for very shallow depths is neglected, the overall relationships of $\mu_{\text {pelagic }}$ and $\mu_{\text {benthic }}$ with total depth $(H)$ are opposite: $\mu_{\text {pelagic generally }}$ increases for smaller $H$, and $\mu_{\text {benthic }}$ becomes more negative for smaller $H$ (see Fig. $3 b, c$ ). Thus, for particular values of $k_{t}$ and $\alpha$, we would expect the $\mu_{\text {pelagic }}$ and $-\mu_{\text {benthic }}$ curves to cross each other at a point representing an exact balance between net light-driven production and consumption by the benthos (i.e. $\mu_{\mathrm{eff}}=0$, or 'balanced population growth') Because of the simplicity of the $\mu_{\text {benthic }}$ function (Eq. 17), we can easily calculate the 'critical' benthic grazing rate at which this balance occurs for a given $H$ (assumed constant), $k_{t_{1}}$ and combination of biological/environmental parameters. This critical grazing rate, $\alpha_{x^{\prime}}$ is plotted as a function of $H$ for several $k_{l}$ values in Fig 4. For a given $k_{1}, \alpha_{x}$ is where a vertical line corresponding to a choseñ depth intersects the curve. Any grazing rate above the $\alpha_{x}-H$ curve results in negative effective growth, and any grazing rate below the curve results in positive effective growth. For example, Point A on Fig. 4 represents a deep, clear site in SSFB (see also Fig. 2). For $H=15 \mathrm{~m}$ and $k_{t}=1.5 \mathrm{~m}^{-1}$, the critical benthic grazing rate $\alpha_{x}=0.7 \mathrm{~m}^{3} \mathrm{~m}^{-2} \mathrm{~d}^{-1}$. Therefore, any grazing rate greater than about $0.7 \mathrm{~m}^{3} \mathrm{~m}^{-2} \mathrm{~d}^{-1}$ will result in locally negative net growth; any grazing rate less than that $\alpha_{x}$ will result in positive net growth. Compare this with a shallow, turbid site represented by Point B in Fig. 4. In this case, $H=1.5 \mathrm{~m}$ and $k_{l}=10 \mathrm{~m}^{-1}$, and the critical grazing rate is $\alpha_{x} \approx 0.2 \mathrm{~m}^{3} \mathrm{~m}^{-2} \mathrm{~d}^{-1}$, much smaller than the $\alpha_{x}$ associated with the deep, clear site. Thus, within one estuary, $\alpha_{x}$ can easily vary 3 -fold. 


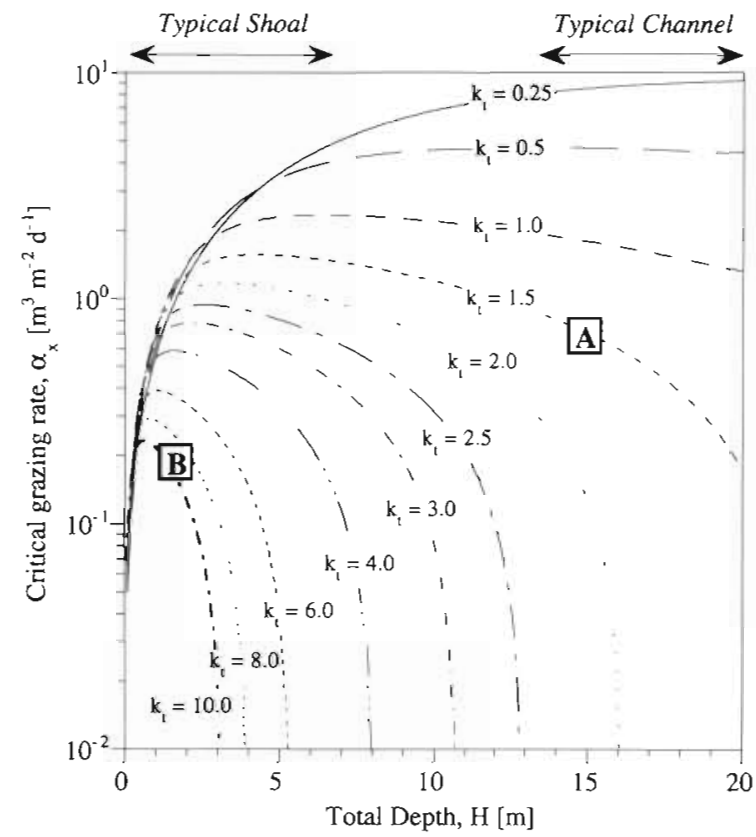

Fig. 4. $\alpha_{x}$ (the benthic grazing rate required to balance all production) versus total depth $(H)$ for several values of light attenuation coefficient, $k_{t}$ (in $\mathrm{m}^{-1}$ ). Values of other biological and environmental parameters are listed in Table 1. A and B: a deep clear site and a shallow turbid site, respectively, in SSFB (see Fig. 2)

There are several features to note from the $\alpha_{x}-H$ plot in Fig. 4. First, $\alpha_{x}$ generally increases for decreasing $k_{t}$ since a lower $k_{l}$ implies greater light availability, more rapid growth, and therefore a larger grazing rate to offset production. Conversely, for very large $k_{i}$, irradiance is very low; therefore, only a small grazing rate is required to balance pelagic production. Second, $\alpha_{x}$ generally changes much more rapidly for shallow depths, which is consistent with the steeper slope of the $\mu_{\text {pelagic }}-H$ curve (Fig. $3 \mathrm{~b}$ ) and the $\mu_{\text {benthic }}-H$ curve (Fig. 3c) for small $H$.

Third, for most cases, the critical grazing rate $\alpha_{x}$ increases, peaks, and then decreases with increasing $H$. The 'peak' is associated with an $H$ that optimizes bloom potential, as measured by the largest allowable benthic grazing rate for balanced population growth. On the left side of the 'peak', $\alpha_{x}$ increases as $H$ increases. Cases where the slope of the $\alpha_{x}-H$ curve is positive are associated primarily with lower $k_{t}$ and smaller $H$ (i.e. greater depth-averaged irradiance). Thus, as a high-irradiance water column deepens, the benthic suspension feeders must filter at a faster rate if they are to balance production. This is due to the rapid light-driven growth coupled with the decreased benthic control associated with larger $H$. In this highirradiance case, water column deepening may affect bloom development most significantly by regulating the effectiveness of grazing (i.e. the $\mu_{\text {eff }}-H$ relationship is primarily grazing-limited). On the right side of the $\alpha_{x}$ 'peak', however, $\alpha_{x}$ decreases as $H$ increases. Cases where the slope of the $\alpha_{x}-H$ curve is negative are associated primarily with higher $k_{t}$ and larger $H$ (i.e. lower depth-averaged irradiance). In this regime, light may limit net production, especially if the water column is deep; therefore, progressively smaller grazing rates would balance production for increasingly deeper water columns. Thus, in a low-irradiance environment, water column deepening may control bloom development primarily by limiting light (i.e. the $\mu_{\mathrm{e} f}-H$ relationship is primarily light-limited). For the range of $H$ and biological/environmental parameters chosen (see Table 1), the curve associated with $k_{t}=0.25 \mathrm{~m}^{-1}$ does not exhibit a negative slope regime. Such extremely low turbidity results in irradiance which is high enough (even in deep water columns) to ensure that the $\mu_{\text {eir }}-H$ relationship is not light-limited. In SSFB, $k_{l}$ is rarely below $1.0 \mathrm{~m}^{-1}$. Thus, in the shallow parts of SSFB variations in $H$ will most significantly impact a bloom by controlling the grazing effect, while variability of $H$ in the deeper regions is most important as a means of regulating the light field.

The final notable feature on Fig. 4 is the cross-over of the $\alpha_{x}-H$ curves themselves for very shallow depths. The curves associated with the lowest $k_{\imath}$ values (representing the highest levels of depth-averaged irradiance) cross below the curves associated with the larger $k_{t}$ values. Essentially, for a very shallow and clear water column, the negative impact of high irradiance on the chl:C ratio causes $\mu_{\text {pelagic }}$ to decrease (see $H=0$ to $2 \mathrm{~m}$ range in Fig. $3 \mathrm{~b}$ ), thus decreasing the benthic grazing rate which would balance population growth.

\section{Trends and implications}

With the preceding concepts and examples in mind, we now explore some of the trends and implications rooted in the relationships between 'local' processes. Specifically, we will demonstrate the following: (1) For a well-mixed estuary with low benthic grazing rates and high turbidity, effective growth rates are higher in the shallow regions than in the deep regions. (2) For a well-mixed estuary with rapid benthic grazing and low turbidity, effective growth rates are higher in the moderately deep and deep regions than in the shallow regions. (3) The influence of tidal fluctuations in water column height on effective growth rates is pronounced in the very shallow regions and relatively insignificant in the deeper regions. 
High $k_{\ell}$ /low $\alpha$ versus low $k_{t} /$ high $\alpha$ conditions

In this section, we use a variation of the $\alpha_{x}-H$ plot to demonstrate that for high turbidity $\left(k_{t}\right)$ and low benthic grazing $(\alpha)$, effective growth rate $\left(\mu_{\text {eff }}\right)$ is higher in the shallow regions, but, for low $k_{t}$ and high $\alpha_{\text {, effective }}$ growth rate is higher in moderately deep and deep regions. Fig. 5 shows critical benthic grazing rate $\left(\alpha_{x}\right)$ versus $H$ for 2 values of $k_{t}, k_{t}^{\text {high }}$ and $k_{t}^{\text {low }}$. Also shown are horizontal lines representing 2 hypothetical grazing rates, $\alpha^{\text {high }}$ and $\alpha^{\text {low }}$. As mentioned above, for a given $k_{l}$ and $H_{1}$ any grazing rate above the $\alpha_{x}$-H curve results in negative effective growth, and any grazing rate below the curve results in positive effective growth.

If we consider the $k_{t}^{\text {low }} / \alpha^{\text {high }}$ case, we notice that the horizontal line representing the hypothetical benthic grazing rate falls above the $\alpha_{x}-H$ curve for small $H$ and below the curve for large $H_{1}$ since the $\alpha_{x}\left(k_{i}^{\text {low }}\right)$ curve has positive or approximately zero slope for all depths plotted. Thus, for these $k_{t}^{\text {low }} / \alpha^{\text {high }}$ conditions, a deep water column is more likely to sustain a positive $\mu_{\text {eff }}$ than a shallow water column. On the other hand, for the $k_{t}^{\text {high }} / \alpha^{\text {low }}$ case, the horizontal line representing the hypothetical grazing rate generally falls below the $\alpha_{x}-H$ curve for small $H$, and above the curve for large $H$, since, except for extremely small $H$, the slope of the $\alpha_{x}\left(k_{t}^{\text {high }}\right)$ curve is sharply negative. For these $k_{l}^{i, i n h} / \alpha^{\text {low }}$ conditions, therefore, a shallow water column is more likely to sustain a positive $\mu_{\text {eff }}$ than a deep water column. These results show that shallow domains are not always net sources of phytoplankton biomass, and that blooms can develop more rapidly in shallow or deep regions, depending on the local balance between light-limited growth ( $\mu_{\text {pelagic }}$ ) and depth-scaled benthic grazing ( $\mu_{\text {benthic }}$ ).

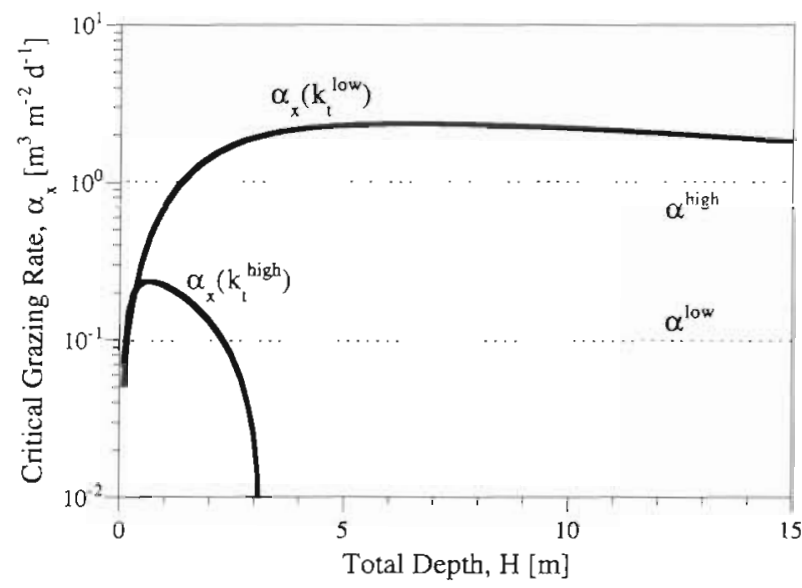

Fig. 5. $\alpha_{x}$ (critical benthic grazing rate) versus $H$ (total depth) for $k_{t}^{\text {low }}=1.0 \mathrm{~m}^{-1}$ (low turbidity) and $k_{t}^{\text {high }}=10 \mathrm{~m}^{-1}$ (high turbidity). Horizontal dotted lines: 2 hypothetical benthic grazing rates, $\alpha^{\text {high }}=1.0 \mathrm{~m}^{3} \mathrm{~m}^{-2} \mathrm{~d}^{-1}$ and $\alpha^{\text {low }}=0.1 \mathrm{~m}^{3} \mathrm{~m}^{-2} \mathrm{~d}^{-1}$

\section{Effects of tidal shallowing and deepening}

In this section we demonstrate the effects of tidal shallowing and deepening of the water column on $\mu_{\text {eit }}$ in the presence of benthic grazing. Again, we show $\alpha_{x}-H$ curves for low and high turbidity cases for 2 different tidally averaged depths, $\bar{H}=1.5 \mathrm{~m}$ (Fig. 6a) and $\bar{H}=5 \mathrm{~m}$ (Fig. 6b). Because we are considering an $H$ which varies in time, we calculated $\alpha_{x}$ separately for each mean depth using a chl:C based on the average daily irradiance over the associated tidal range of depths. We include annotations indicating typical depths for high and low water during spring and neap tides for the 2 different mean depths in SSFB. The average tidal range in SSFB is $\approx 2 \mathrm{~m}$, decreasing somewhat during neap tide and increasing during spring tide.
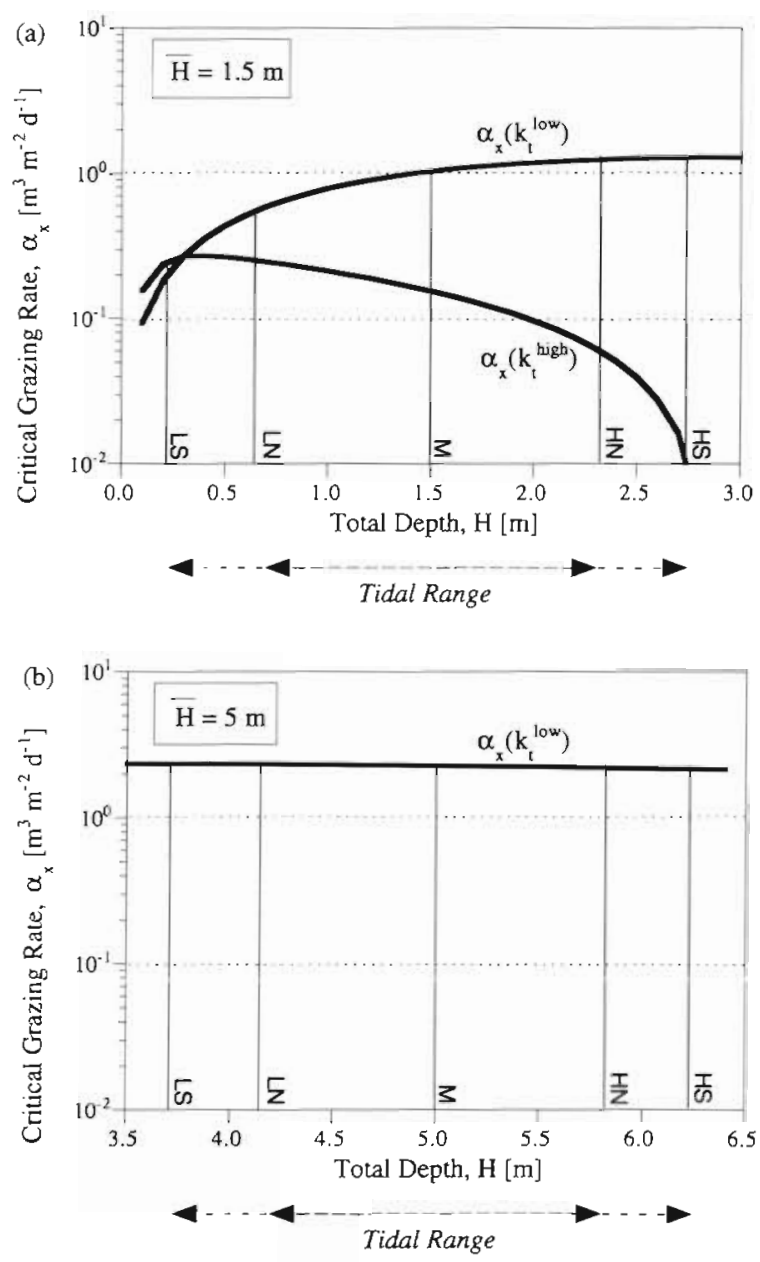

Fig. 6. $\alpha_{x}$ (critical benthic grazing rate) versus $H$ (total depth) for $k_{f}^{\text {low }}=1.0 \mathrm{~m}^{-1}$ (low turbidity) and $k_{t}^{\text {high }}=10 \mathrm{~m}^{-1}$ (high turbidity) for mean heights (a) $\bar{H}=1.5 \mathrm{~m}$ and (b) $\bar{H}=5.0 \mathrm{~m}$. Vertical lines: typical tidal elevations for high and low water during spring and neap tides in SSFB. M: mean water column height $(\bar{H})$, LN: low water, neap tide, HS: high water, spring tide, etc. 
Notice that for both values of $k_{i}$ the slope of an $\alpha_{x}-H$ curve is generally steeper for smaller $\bar{H}$ (Fig. 6a) than for larger $\bar{H}$ (Fig. 6b). For this reason, we see that the fluctuation in $H$ over a tidal cycle may result in a wide range of $\alpha_{x}$ if the mean depth is relatively small (Fig. 6a). For example, for low $k_{t}$ and some large benthic grazing rate (e.g. $\alpha \approx 1 \mathrm{~m}^{3} \mathrm{~m}^{-2} \mathrm{~d}^{-1}$ ), $\mu_{\text {et }}$ in a very shallow environment may be negative during low tide and positive during high tide, due to grazing regulation. For high $k_{l}$ and some small benthic grazing rate (e.g. $\alpha \approx 0.1 \mathrm{~m}^{3} \mathrm{~m}^{-2} \mathrm{~d}^{-1}$ ), $\mu_{\text {eff }}$ in a very shallow environment may be positive during low tide and negative during high tide, due to light limitation. For a larger mean depth (Fig. 6b) we see, first of all, that the $k_{t}^{\text {high }}$ curve is not visible. This is because $\mu_{\text {pelagic }}$ for the deeper, turbid water column is always negative (i.e. respiration and zooplankton grazing losses are greater than gross photosynthesis), resulting in negative $\alpha_{x}$. In other words, for this deeper, turbid water column, only a benthic source could produce a bloom. This scenario is not considered here and so is not plotted. The $k_{t}^{\text {low }}$ curve is shown, however. In this case, the change in $\alpha_{x}$ is not great from one end of the tidal range to the other (slope $\approx 0$ ); therefore, $\mu_{\mathrm{eff}}$ will not change significantly from high to low tide.

In Fig. 7, we demonstrate the effects of semidiurnal shallowing and deepening on benthic grazing strength, $\mu_{\text {benthic }}$ (Fig. 7a), and effective growth rate, $\mu_{\text {efi }}$ (Fig. 7b,c), for 2 different mean depths found across the SSFB shoals $(\bar{H}=1.5$ and $5.0 \mathrm{~m})$. Time series of both instantaneous and day-averaged $\mu_{\text {eff }}$ are shown for $\alpha=0.6 \mathrm{~m}^{3} \mathrm{~m}^{-2} \mathrm{~d}^{-1}$ and $k_{t}=2 \mathrm{~m}^{-1}$. For the shallower location, the large downward spikes in instantaneous $\mu_{\text {eff }}$ (Fig 7 b) are due to a greatly enhanced grazing effect during lower low water (Fig. 7a). Because tidal range increases on spring tides and decreases on neap tides, lower low water is extra low during spring tide, resulting in further enhanced grazing effects and more strongly negative instantaneous $\mu_{\mathrm{eff}}$ during spring tide/lower low water than during neap tide/ lower low water. The effect of grazing at the deeper station shows far less temporal variability (Fig. 7a), resulting in very little tidal-scale variation in $\mu_{e f 1}$ (Fig. 7c)

The effect of spring-neap variations in tidal range on day-averaged $\mu_{\text {eff }}$ is also shown. Although dayaveraged $\mu_{\text {eff }}$ alone does not perfectly reflect the nonlinear dynamics of phytoplankton population growth and decline over the course of a day, we use it here as an indicator of how local conditions change as a function of tidal range over the spring-neap cycle. Whereas $\mu_{\text {eff }}$ in the deeper water column $(\bar{H}=5 \mathrm{~m})$ shows only small semidiurnal oscillations and consequently no discernable spring-neap variation (Fig. $7 \mathrm{C}$ ), day-averaged $\mu_{\text {eff }}$ for the shallower water column $(\bar{H}=1.5 \mathrm{~m})$ is neg-

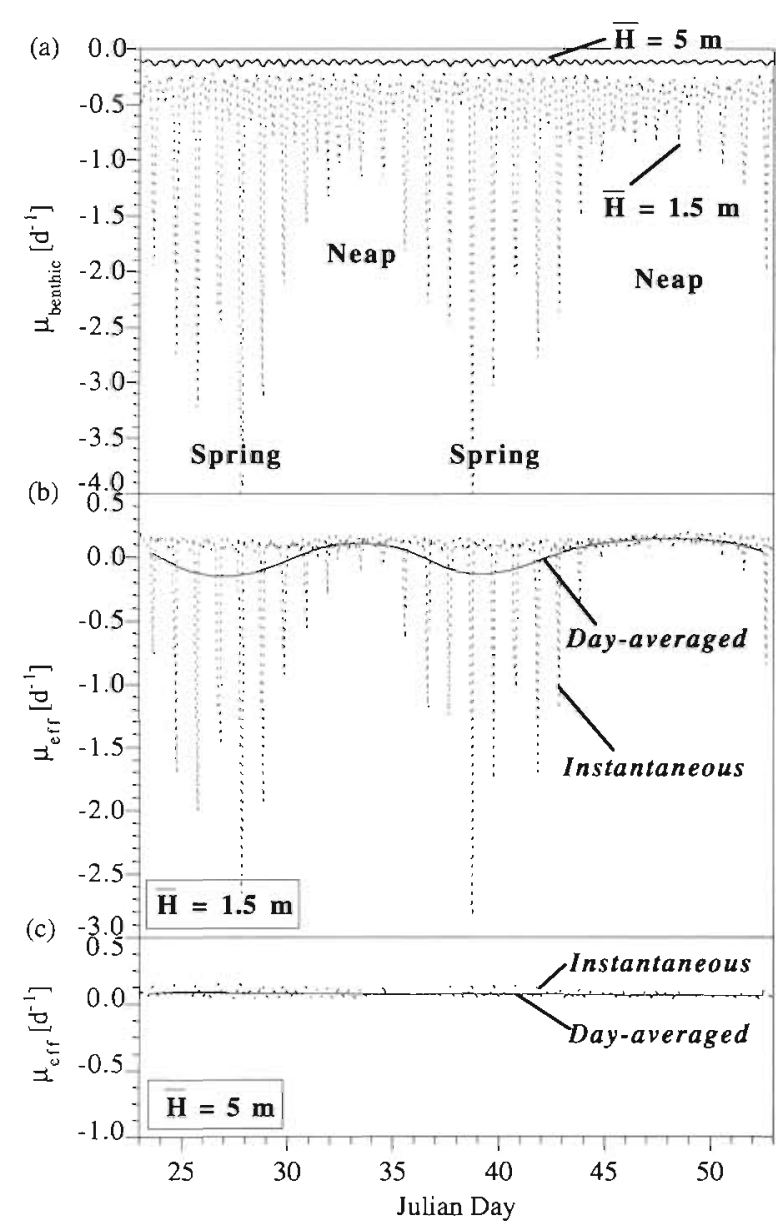

Fig. 7. Time series of (a) $\mu_{\text {benthic (grazing effect) and (b,c) }}$ $\mu_{\text {eff }}$ (total phytoplankton effective growth rate) for mean depths $\bar{H}=1.5$ and $5 \mathrm{~m}$, benthic grazing rate $\alpha=0.6 \mathrm{~m}^{3} \mathrm{~m}^{-2}$ $\mathrm{d}^{-1}$, and turbidity $k_{\mathrm{t}}=2 \mathrm{~m}^{-1}$

ative on spring tide and positive on neap tide (Fig. $7 \mathrm{~b}$ ). This neap-spring cycle in the balance between local production and consumption in shallow estuaries can be an important mechanism of weekly scale variability of phytoplankton biomass. The periods of rapid phytoplankton biomass growth in SSFB correlate strongly with the spring-neap cycle (Cloern 1991, 1996), and past analyses have suggested that neap-tide blooms are the result of reduced turbulent mixing (Cloern 1991) and suspended sediment concentrations (Cloern et al. 1985, Thompson 1999). Our modeling analysis (Fig. 7) has identified a third possible mechanism of neap-tide blooms in shallow domains: in the presence of benthic grazers, the narrower tidal range and associated higher water levels at lower low water during neap tide dampen the effect of low-tide benthic consumption, resulting in larger growth rates $\left(\mu_{\text {eff }}\right)$ during the lower low water phase of maximum benthic consumption. 
Application to a real estuarine transect

In this section, we illustrate the impact of the mechanisms described above on spatial distributions of $\mu_{\text {eff }}$ in a bathymetrically complex system such as SSFB, and on the temporal evolution of those distributions. By calculating $\mu_{\text {efl }}$ and several related quantities across a lateral transect at different tidal phases, we illustrate that (1) both deep and shallow regions may serve as sources or sinks of phytoplankton biomass, depending on the balance between local production and consumption; and (2) tidal elevation changes can influence the spatial distribution of $\mu_{\text {eff }}$ especially in shallow regions and in the presence of benthic grazing.

For $k_{t}^{\text {high }} / \alpha^{\text {low }}$ and $k_{l}^{\text {low }} / \alpha^{\text {high }}$ scenarios, respectively, Figs, $8 \& 9$ show transverse variations in $H$ and 7 dependent variables $\left(\bar{I}\right.$, chl:C, $\bar{P}, \mu_{\text {pelagic, }} \mu_{\text {benthrc }} \alpha_{x}$ and $\left.\mu_{\text {efi }}\right)$ calculated across the lateral transect indicated in Fig. 2. For each scenario, $k_{t}$ and $\alpha$ are specified as constants across the transect: $k_{t}=10.0 \mathrm{~m}^{-1}$ and $\alpha=0.1 \mathrm{~m}^{3}$ $\mathrm{m}^{-2} \mathrm{~d}^{-1}$ for the $k_{t}^{\text {high }} / \alpha^{\text {low }}$ case, and $k_{t}=$ $1.0 \mathrm{~m}^{-1}$ and $\alpha=1.0 \mathrm{~m}^{3} \mathrm{~m}^{-2} \mathrm{~d}^{-1}$ for the $k_{t}^{\text {low }} / \alpha^{\text {high }}$ case. $\bar{H}$ as well as $H$ at high and low tide (assuming a $2 \mathrm{~m}$ tidal range) are shown, as are 6 of the 7 calculated quantities for each tidal stage. (chl:C is calculated based on the local $24 \mathrm{~h}$ average irradiance and so only 1 curve is shown.)

Spatial variability: Transects of $\mu_{\text {eff }}$ (bottom panel of Figs. 8 \& 9) reflect the different roles a deep region and a shallow region may assume, depending on the clarity of the water and the benthic grazing strength. Transects of $\mu_{\text {eft }}$ for the $k_{t}^{\text {high }} / \alpha^{\text {low }}$ case (minimum $\mu_{\text {eff }}$ in the channel, maximum $\mu_{\text {eff }}$ in the shoals) are very different from the $\mu_{\mathrm{eff}}$ trends for the $k_{t}^{\text {low }} / \alpha^{\text {high }}$ case (generally minimum $\mu_{\text {eff }}$ in the shoals, larger $\mu_{\text {eff }}$ in the deeper regions). Similarly, $\alpha_{x}$ transects are opposite for the 2 scenarios: minimum $\alpha_{x}$ occurs in the channel for $k_{i}^{\text {high }} / \alpha^{\text {low }}$, but minimum $\alpha_{x}$ accurs in the shoals for $k_{f}^{\text {low }} / \alpha^{\text {high }}$. Note that, for the $k_{l}^{\text {low }} / \alpha^{\text {high }}$ case, $\mu_{\text {eff }}$ and $\alpha_{x}$ are maximal at the channel-shoal transition, where the lightgrazing trade-off is optimized.

These trends in spatial variability are rooted in the lateral variation of $\mu_{\text {pelagic }}$ and $\mu_{\text {benthic }}$ For the more turbid $\left(k_{t}^{\text {high }} / \alpha^{\text {law }}\right)$ case, $\mu_{\text {pelagic }}$ (effective growth rate in the absence of benthic grazing) is larger everywhere in the shoals than in the channel because $\bar{I}$ is higher in the shoals (Fig. 8). However, if the water is clearer $\left(k_{t}^{\text {low }} / \alpha^{\text {high }}\right), \mu_{\text {pelagic }}$ is a weakly nonmonotonic function of $H$ (and $\bar{I}$ ), reaching a maximum at approximately $\bar{H}=2 \mathrm{~m}$ (in this case) due to the codependence of $\mu_{\text {pelagic }}$ on chl:C and $\bar{P}$ (Fig. 9). In this low turbidity case, $\bar{I}$ in the shoals is large enough such that chl: $C$ decreases sufficiently to influence $\mu_{\text {pelagici }}$ on the other hand, $\mu_{\text {pelagic }}$ in the channel is always dominated by $\bar{P}$ since $\bar{I}$ never gets very large there. Thus, $\mu_{\text {pelagic, which }}$ may easily double between channel and shoal for even within a compartment), can profoundly influence spatial variability of $\mu_{\text {eff }}$.

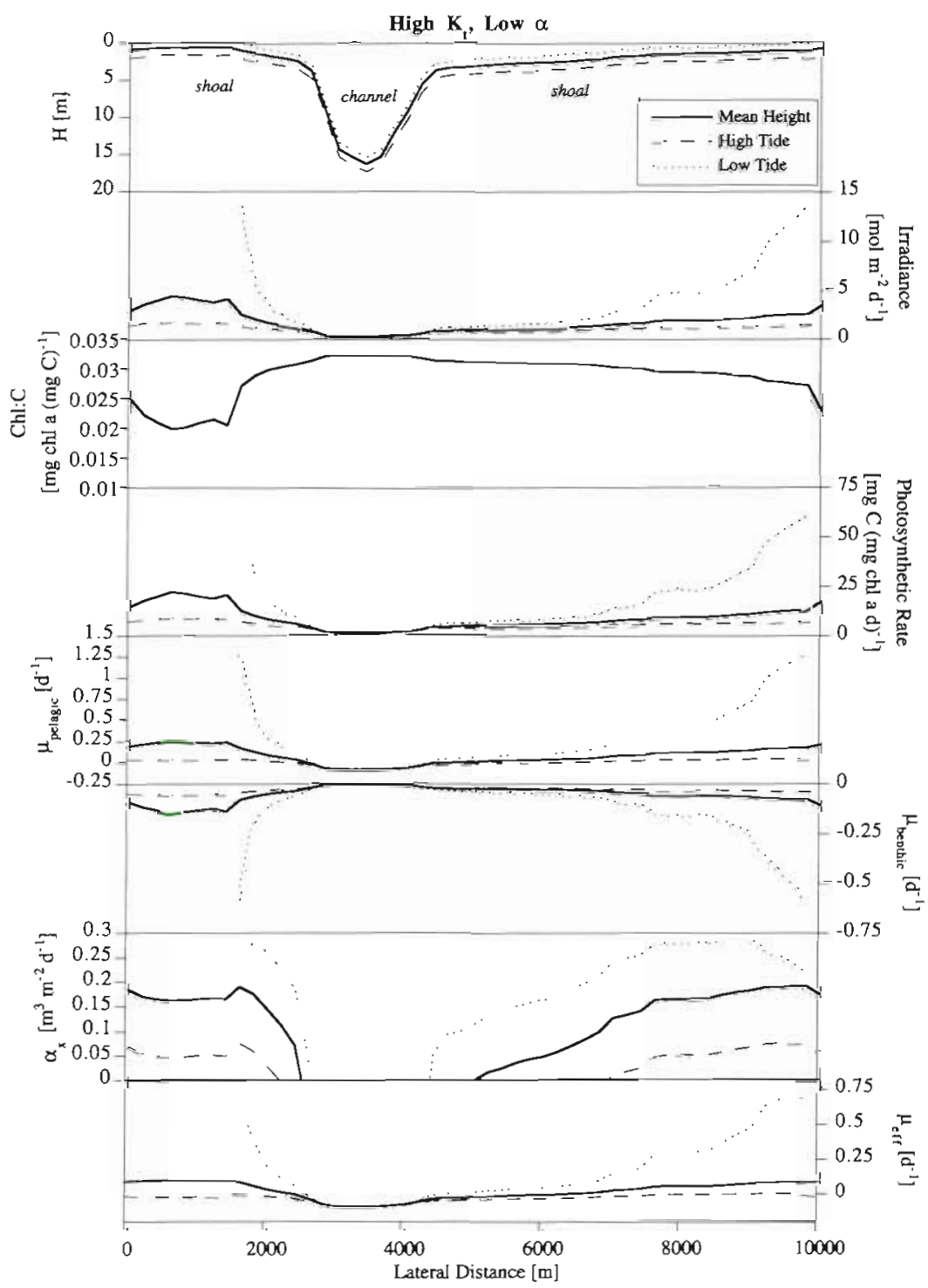

Fig. 8. Lateral transects of water column height $(H)$ and 7 calculated quantities (see Table 1 for definitions) at mean tidal elevation, high water, and low water for the case: high turbidity, low grazing $\left(k_{t}=10.0 \mathrm{~m}^{-1}, \alpha=0.1 \mathrm{~m}^{3} \mathrm{~m}^{-2} \mathrm{~d}^{-1}\right)$ 
Spatial variability of the benthic sink $\mu_{\text {benthic }}$ may also significantly affect lateral distributions of $\mu_{\text {efr }}$. Since $\mu_{\text {eff }}$ depends monotonically on $\alpha$ (via $\mu_{\text {benthuc }}$ ), increased $\alpha$ always decreases $\mu_{\mathrm{eff}}$. Because of the inverse monotonic dependence of $\mu_{\text {benthic }}$ on $H$, phytoplankton growth over the shoals shows a greater sensitivity to benthic grazing than $\mu_{\text {etf }}$ in the channel (see $\mu_{\text {benthic }}$ transects). For this reason, a large benthic grazing rate results in very negative $\mu_{\text {etl }}$ in the shoals

Temporal variability: Semidiurnal shallowing and deepening of the water column also causes great variability in phytoplankton growth rates. In the turbid $k_{i}^{\text {high }} / \alpha^{\text {low }}$ case (Fig. 8), $\mu_{\text {eff }}$ increases as the water column shallows, similar to the increase in $\mu_{\text {pelagic }}$ with de-

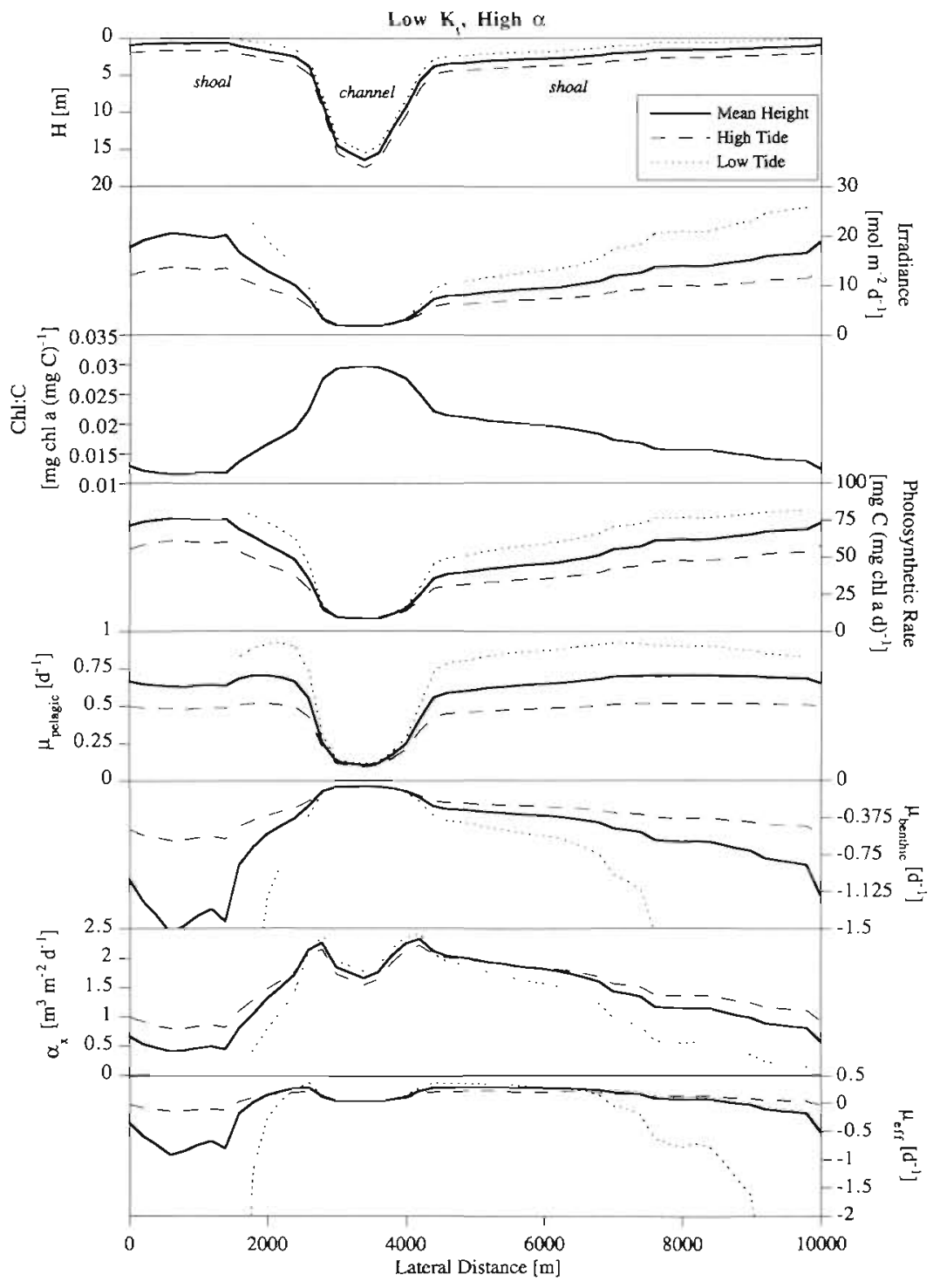

Fig. 9. Lateral transects of water column height $(H)$ and 7 calculated quantities (see Table 1 for definitions) at mean tidal elevation, high water, and low water for the case: low turbidity, high grazing $\left(k_{t}=1.0 \mathrm{~m}^{-1}, \alpha=1.0 \mathrm{~m}^{3} \mathrm{~m}^{-2} \mathrm{~d}^{-1}\right)$ creasing $H$ (since a shallow water column maximizes $\bar{I}$ and since $\mu_{\text {benthic }}$ is not strong enough to counteract the $\mu_{\text {pelagic }}-\bar{I}$ relationship). However, in the $k_{t}^{\text {low }} / \alpha^{\text {high }}$ case (Fig. 9), $\mu_{\text {eff }}$ in the shoals generally decreases as the water column shallows, due to the increasing magnitude of $\mu_{\text {benthic }}$ with decreasing $H$. An exception is in the channel-shoal transition, where the tidal variability of the benthic grazing effect is on the order of the tidal variability of $\mu_{\text {pelagic }}$ and is therefore not as dominant as in the shallower areas.

Tidal changes in surface elevation combined with topographic variability can, therefore, result in a range of spatial-temporal trends in $\mu_{\text {eff }}$ depending on the lightgrazing balance. Temporal effects are most pronounced in shallow regions and have the potential to switch $\mu_{\text {eff }}$ from positive to negative over half a tidal cycle and to result in rapid biomass depletion during low tide in the presence of strong benthic grazing.

\section{CONCLUSIONS}

We have used a depth-averaged representation of phytoplankton growth to explore local phytoplankton dynamics in a shallow estuary. Specifically, we have investigated dynamics which depend upon the local water column height, $H$. Our depth-averaged formulation is based on the assumption that the water column is vertically well-mixed. Although this approximation is strictly valid for shallow systems subjected to strong turbulent mixing, this approach has allowed us to identify a number of potentially important general trends.

The functional relationship between phytoplankton growth rate and water column height is variable, depending on whether the local limitations of growth are dominated by benthic grazing or light availability. Specifically: (1) If the benthic grazing rate is high and turbidity is low (i.e. light is abundant), then the effective phytoplankton growth rate will generally decrease as the water column shallows, spatially or temporally. This is due to the enhanced benthic control on a shallow water column relative to a deep water column. (2) If the benthic grazing rate is small and turbidity is high (i.e. light is limiting), then the effective phytoplankton growth rate will generally increase as the water column shallows, spatially or tem- 
porally. This is due to the greater depth-averaged irradiance in a shallow water column relative to a deep water column. Thus, both shallow and deep regions can serve as sources or sinks for phytoplankton biomass, depending on the relative strength of local light-driven production and benthic consumption. Similarly, either high or low tide can represent maximum production or consumption, depending on the light-grazing balance. Therefore, although phytoplankton biomass is often observed to be highest in the shallow domains of some estuaries, shallow regions are not always sites of positive net phytoplankton population growth and can, under some conditions, act as biomass sinks.

In the presence of benthic grazing, effective phytoplankton growth rates in very shallow environments will exhibit great sensitivity to tidal shallowing and deepening of the water column, potentially switching from source to sink over a $6 \mathrm{~h}$ period. This effect is due primarily to the enhanced depletion of phytoplankton by the benthos in shallow water columns; however, tidal variations in depth-averaged irradiance may have an effect as well. Effective growth rates in deep regions are much less sensitive to semidiurnal tidal variations in water depth and maintain relatively static values. Thus, with respect to bloom development, well-mixed shoals are much more dynamic environments than deep channel regions, exhibiting a broader range of effective growth rates over tidal time scales and potentially acting as a significant source and sink for phytoplankton biomass.

The semidiurnal variability in effective phytoplankton growth rates at shallow sites translates into spring-neap variability as well, due to the variation in tidal range over the spring-neap cycle. In fact, variability in tidal range alone can result in day-averaged effective growth rates in shallow regions which are positive during neap tide and negative during spring tide. Weekly time scale variability in tidal range, combined with nonzero benthic grazing, may therefore offer a mechanism for the common occurrence of bloom initiation during neap tides.

In the companion to this paper, Lucas et al. (1999) discuss transport-related mechanisms which, in conjunction with the local mechanisms described above, may control if and where phytoplankton blooms will occur.

Acknowledgements, L.V.L., J.R.K., and S.G.M. wish to acknowledge the support of the NSF Division of Biological Oceanography through grant number OCE-9504081, as well as the Josephine De Kármán Foundation, NASA, and the EPA, through grant number CE00960502. J.E.C. and J.K.T. received support for this study from the USGS Toxic Substances Hydrology Program. We thank Vincenzo Casulli and Ralph Cheng for making the TRIM2D model available to us, and Ed Gross for his help in implementing our additions. L.V.L. performed this work as part of her dissertation research at Stanford University.

\section{LITERATURE CITED}

Alpine AE, Cloern JE (1988) Phytoplankton growth rates in a light-limited environment, San Francisco Bay. Mar Ecol Prog Ser 44:167-173

Anderson DM, Garrison DJ (eds) (1997) The ecology and oceanography of harmful algal blooms. Limnol Oceanogr 42:1009-1305

Bannister TT (1974) A general theory of steady state phytoplankton growth in a nutrient saturated mixed layer. Limnol Oceanogr 19:13-30

Caffrey JM, Cole BE, Cloern JE, Rudek JR, Tyler AC, Jassby AD (1994) Studies of the San Francisco Bay, California, estuarine ecosystem: pilot regional monitoring results, 1993. Open-File Report 94-82. US Geological Survey, Menlo Park, CA

Casulli V (1990a) Numerical simulation of shallow water flow. In: Gambolati G, Rinaldo A, Brebbia CA, Gray WG, Pinder GF (eds) Computational methods in surface water hydrology. Springer-Verlag, Berlin, p 13-22

Casulli V (1990b) Semi-implicit finite-difference methods for the two-dimensional shallow water equations. J Comput Phys 86:56-74

Cheng RT, Casulli V, Gartner JW (1993) Tidal, residual, intertidal mudflat (TRIM) model and its applications to San Francisco Bay, California. Estuar Coast Shelf Sci 36:235-280

Cloern JE (1982) Does the benthos control phytoplankton biomass in South San Francisco Bay? Mar Ecol Prog Ser 9: 191-202

Cloern JE (1991) Tidal stirring and phytoplankton bloom dynamics in an estuary. J Mar Res 49:203-221

Cloern JE (1996) Phytoplankton bloom dynamics in coastal ecosystems: a review with some general lessons from sustained investigation of San Francisco Bay, California. Rev Geophys 34(2):127-168

Cloern JE, Cheng RT (1981) Simulation model of Skeletonema costatum population dynamics in Northern San Francisco Bay, California. Estuar Coast Shelf Sci 12:83-100

Cloern JE, Cole BE, Wong RLJ, Alpine AE (1985) Temporal dynamics of estuarine phytoplankton: a case study of San Francisco Bay. Hydrobiologia 129:153-176

Cloern JE, Grenz C, Lucas LV (1995) An empirical model of the phytoplankton chlorophyll:carbon ratio-the conversion factor between productivity and growth rate. Limnol Oceanogr 40(7):1313-1321

Colijn F (1982) Light absorption in the waters of the EmsDollard estuary and its consequences for the growth of phytoplankton and microphytobenthos. Neth J Sea Res 15:196-216

Conomos TJ, Smith RE, Gartner JW (1985) Environmental setting of San Francisco Bay. Hydrobiologia 129:1-12

Edmunds $J \mathrm{~L}$, Cole BE, Cloern JE, Caffrey JM, Jassby AD (1995) Studies of the San Francisco Bay, California, estuarine ecosystem: pilot regional monitoring results, 1994. Open-File Report 95-378. US Geological Survey, Menlo Park, CA

Fischer HB, List EJ, Koh RCY, Imberger J, Brooks NH (1979) Mixing in inland and coastal waters. Academic Press, Inc, San Diego, CA

Franks PJS (1992) Phytoplankton blooms at fronts: patterns, scales, and physical forcing mechanisms. Rev Aquat Sci 6 : $121-137$

Huzzey LM, Cloern JE, Powell TM (1990) Episodic changes in lateral transport and phytoplankton distribution in South San Francisco Bay. Limnol Oceanogr 35(2):472-478

Koseff JR, Holen JK, Monismith SG, Cloern JE (1993) Coupled effects of vertical mixing and benthic grazing on 
phytoplankton populations in shallow, turbid estuaries. J Mar Res 51:843-868

Legendre L (1990) The significance of microalgal blooms for fisheries and for the export of particulate organic carbon in oceans. J Plankton Res 12:681-699

Le Pape O, Del Amo Y, Ménesguen A, Aminot A, Quéguiner $B$, Tréguer $P(1996)$ Resistance of a coastal ecosystem to increasing eutrophic conditions: the Bay of Brest (France), a semi-enclosed zone of Western Europe. Cont Shelf Res $16: 1885-1907$

Lucas LV (1997) A numerical investigation of coupled hydrodynamics and phytoplankton dynamics in shallow estuaries. PhD thesis, Stanford University

Lucas LV, Cloern JE, Koseff JR, Monismith SG, Thompson JK (1998) Does the Sverdrup Critical Depth Model explain bloom dynamics in estuaries? J Mar Res 56(2):375-415

Lucas LV, Koseff JR, Monismith SG, Cloern JE, Thompson JK (1999) Processes governing phytoplankton blooms in estuaries. II. The role of horizontal transport. Mar Ecol Prog Ser $187: 17-30$

Malone TC, Kemp WM, Ducklow HW, Boynton WR, Tuttle $\mathrm{JH}$, Jones RB (1986) Lateral variation in the production and fate of phytoplankton in a partially stratified estuary. Mar Ecol Prog Ser 32:149-160

O'Riordan CA, Monismith SG, Koseff JR (1995) The effect of bivalve excurrent jet dynamics on mass transfer in a benthic boundary layer. Limnol Oceanogr 40(2):330-344

Pennock JR (1985) Chlorophyll distributions in the Delaware estuary: regulation by light-limitation. Estuar Coast Shelf Sci 21:711-725

Platt T, Sathyendranath S, Ravindran P (1990) Primary pro-

Editorial responsibility: Otto Kinne (Editor),

Oldendorf/Luhe, Germany duction by phytoplankton: analytic solutions for daily rates per unit area of water surface. Proc R Soc Lond Biol Sci (Ser B) 241:101-111

Platt T, Bird DF, Sathyendranath S (1991) Critical depth and marine primary production. Proc R Soc Lond Biol Sci (Ser B) 246:205-218

Relexans JC, Meybeck M, Billen G, Brugeaille M, Etcheber $H$. Somville $M$ (1988) Algal and microbial processes involved in particulate organic matter dynamics in the Loire estuary. Estuar Coast Shelf Sci 27:625-644

Signell RP, Butman B (1992) Modeling tidal exchange and dispersion in Boston Harbor $J$ Geophys Res $97(\mathrm{ClO})$ : 15591-15606

Simpson JH, Brown J, Matthews J, Allen G (1990) Tidal straining, density currents, and stirring in the control of estuarine stratification. Estuaries 13:125-132

Thompson JK (1999) The effect of infaunal bivalve grazing on phytoplankton bloom development in south San Francisco Bay. PhD thesis, Stanford University

Vidergar LL, Koseff JR, Monismith SG (1993) Numerical models of phytoplankton dynamics for shallow estuaries. In: Shen HW, Su ST, Wen F (eds) Hydraulic Engineering '93. American Society of Civil Engineers, New York, p 1025-1030

Webb WL, Newton M, Starr D (1974) Carbon dioxide exchange of Alnus rubra: a mathematical model. Oecologia 17:281-291

Zimmerman JTF (1976) Mixing and flushing of tidal embayments in the Western Dutch Wadden Sea, Part I: Distribution of salinity and calculation of mixing time scales. Neth J Sea Res 10(2):149-191

Submitted: September 1, 1998; Accepted: May 10, 1999 Proofs received from author(s): September 17, 1999 